\title{
The Biophysical Controls of Macroalgal Growth on Subtropical Reefs
}

\author{
Cesar Augusto Marcelino Mendes Cordeiro ${ }^{1,2 * t}$, Alastair R. Harborne ${ }^{3}$ and \\ Carlos Eduardo Leite Ferreira ${ }^{1}$
}

${ }^{1}$ Reef Systems Ecology and Conservation Lab, Universidade Federal Fluminense, Niterói, Brazil, ${ }^{2}$ Federal University of Rio de Janeiro, Rio de Janeiro, Brazil, ${ }^{3}$ Tropical Fish Ecology Lab, Florida International University, North Miami, FL, United States

OPEN ACCESS

Edited by:

Punyasloke Bhadury,

Indian Institute of Science Education and Research Kolkata, India

Reviewed by:

Tiago José Pereira, University of Georgia, United States

Christopher Barrio Froján,

Seascape Consultants Ltd,

United Kingdom

*Correspondence:

Cesar Augusto Marcelino Mendes Cordeiro

cammcordeiro@id.uff.br

tORCID:

Cesar Augusto Marcelino Mendes

Cordeiro

orcid.org/0000-0003-4960-450

Specialty section:

This article was submitted to Marine Biology

a section of the journal

Frontiers in Marine Science

Received: 26 February 2020 Accepted: 02 June 2020

Published: 07 July 2020

Citation:

Cordeiro CAMM, Harborne AR and Ferreira CEL (2020) The Biophysical Controls of Macroalgal

Growth on Subtropical Reefs.

Front. Mar. Sci. 7:488.

doi: 10.3389/fmars.2020.00488
The importance of macro-grazers in controlling macroalgal cover has long been recognized on tropical and temperate reefs, with fishes of primary importance on the former and sea urchins on the latter. However, the functional role of herbivorous urchins and fishes on subtropical marginal reefs remains poorly explored. To evaluate the relative importance of fishes and urchins on marginal subtropical reefs, this study used exclusion devices (excluding all grazers, fishes, or urchins) at two depths (1-2, 5-6 m) on Brazilian rocky reefs. Depth influenced responses within cages, with shallow sites changing from patchy barrens (dominated by crustose coralline algae) to epilithic algae-dominated within exclusion treatments, and sea urchins being the primary driver of benthic dynamics. In deeper water, the growth and senescence cycle of Sargassum species drove benthic dynamics and was associated with the season of higher intensity of upwelling events. No clear influence of herbivorous fishes was detected on benthic cover at either depth, despite biomasses similar to comparable tropical reefs where they do control macroalgal populations. Thus, abiotic factors seem to be a strong driver of benthic dynamics in the studied region, and top-down processes act only at shallow depths. Consequently, despite Brazilian subtropical communities being dominated by tropical species, the ecological drivers of these reefs may be more similar to temperate systems.

\section{Keywords: marginal reefs, grazers, upwelling, exclusion experiments, Brazil}

\section{INTRODUCTION}

Herbivory is a critical process controlling the distribution and diversity of macroalgal cover in many marine ecosystems (Lubchenco and Gaines, 1981; Bonaldo et al., 2014), and consequently determines the spatial organization and dynamics of benthic assemblages (Horn, 1989; Bozec and Mumby, 2015). For example, on tropical and temperate reefs, herbivory is an important process modulating shallow marine benthic assemblages (Steneck et al., 2017). These effects are well demonstrated on Caribbean reefs, where herbivorous feeding limits algal growth while benefiting coral demographics, such as increasing larval settlement and consequently increasing reef resilience (Burkepile and Hay, 2006; Bozec and Mumby, 2015). The role of herbivorous fishes have also expanded since the mass mortality of the urchin Diadema antillarum in the Caribbean (Lessios et al., 2001; Lessios, 2016). Reef benthic dynamics are also influenced by abiotic factors including 
depth, wave exposure, and nutrient concentrations (Mumby et al., 2006; Mumby and Hastings, 2008; Roff et al., 2015).

In temperate regions, sea urchins are recognized as keystone species in top-down processes (Tuya et al., 2004a), especially influencing the dynamics of kelp forests and whole ecosystem energetics (e.g., Estes and Palmisano, 1974; Kriegisch et al., 2016). However, seasonal variation in benthic composition may create cycles of expansion and contraction of 'barren' zones irrespective of sea urchins' grazing action, sometimes masking herbivory effects (Sala and Boudouresque, 1997). Urchin grazing can also be significantly affected by declines in predator populations, which can induce high levels of grazing and bioerosion on benthic communities, leading to changes that can last for years, and having direct consequences on reef productivity and diversity (Sheppard-Brennand et al., 2017).

How nutrients affect algal cover across tropical and temperate reefs is still debated, with different approaches leading to divergent conclusions. Generally, the addition of nutrients increases algal growth and biomass, but compensation by herbivores and algal composition can modulate responses and determine benthic dynamics (Burkepile and Hay, 2006; Poore et al., 2012). Although, the increase in nutrients is usually associated with decreasing water quality (D'Angelo and Wiedermann, 2014), in upwelling systems this condition is common and beneficial for some reef organisms, such as corals (Stuhldreier et al., 2016), but the effects of herbivores may be minimized during upwelling events (Sellers et al., 2019).

Although there is a large and growing literature on herbivory and nutrients on tropical and temperate reefs, subtropical regions are rarely considered (Bennett and Bellwood, 2011), despite their ecological and economic importance. Furthermore, these marginal systems will probably be the first to experience effects from species range expansions, especially herbivorous fishes (Vergés et al., 2014). Understanding the natural functional roles of different grazers is critical, but the relative importance of sea urchins and herbivorous fishes in affecting benthic dynamics in marginal reefs remains unclear.

This study uses exclusion treatments (excluding sea urchins, fishes, and both) to examine the effects of macro-grazers on benthic dynamics in the southwestern Atlantic, and the relative importance of herbivorous fishes and sea urchins, temperature and nutrients. Since the studied reefs lie in a subtropical zone dominated by grazing and benthic species with tropical affinities (Cordeiro et al., 2014, 2016), we hypothesized that herbivorous fishes are the primary control of benthic cover irrespective of abiotic drivers (temperature, depth and nutrients).

\section{MATERIALS AND METHODS}

\section{Study Site}

The Arraial do Cabo region consists of an isthmus and four islands (Figure 1), mostly surrounded by rocky shores. The region was declared a marine extractive reserve in 1997, where only traditional fishers are allowed to exploit natural resources. However, no-take areas are absent and general enforcement is limited.
Small-scale upwelling processes often occur in the region because of the prevailing winds (north-easterlies) and coastal morphology, where upwelling water is characterized by temperatures below $20^{\circ} \mathrm{C}$ (originating from the South Atlantic Central Water mass) and higher nutrient loads, especially nitrate and ammonia (Valentin, 1984; Lanari and Coutinho, 2014). It is worth noting that there is no significant freshwater input (i.e., rivers) within a $40 \mathrm{~km}$ radius. This region of Brazil has a tropical monsoon climate with dry 'winters' (Alvares et al., 2013), and Arraial do Cabo has very low precipitation $\left(<850 \mathrm{~mm}\right.$ year $^{-1}$, INMET, 2020). Although this climatic classification is well established, the oceanographic conditions are basically wind-driven. Upwelling events are more frequent and intense during the rainy season (stronger north-easterlies) roughly from mid-September to March, while the dry season (April to August) has typically mild winds and a larger influence of downwelling and cold fronts (S-SW winds) (Mazzuco et al., 2018). Furthermore, the intrusion of the South Atlantic Central Water mass on continental shelf biota of this large portion of the Southwestern Atlantic, which bears majority of its rocky shores, is widely recognized (e.g., De Léo and Pires-Vanin, 2006; Arantes et al., 2009; Nogueira-Júnior and Brandini, 2018). Here we treated the meteorological seasons (rainy and dry) as upwelling and non-upwelling periods to account for the main temporal processes.

Shallower depths $(1-4 \mathrm{~m})$ have higher abundances of sea urchins, with the presence of mosaics of "barren" patches, epilithic algal matrix (EAM), and sessile invertebrates (Cordeiro et al., 2014). The deeper reef areas ( $>4 \mathrm{~m}$ ) are mainly covered by macroalgae and EAM, with the presence of massive coral colonies (Cordeiro et al., 2014). Epilithic algal matrix is here dominated by filamentous algae (Supplementary Table S1), with articulated coralline algae (ACA) considered as a separate group due to its distinct structural characteristics (Steneck and Dethier, 1994). Surgeonfish are the dominant scrapper-detritivore group, followed by parrotfishes and sea chubs that are evenly distributed across depths and sites in the area (Cordeiro et al., 2016).

High nitrogen concentration is a characteristic effect of upwelling events in the north of Rio de Janeiro state $(>2 \mu \mathrm{M}-$ dissolved inorganic nitrogen, Valentin, 1984; Gonçalves, 1999; Fernandes et al., 2017), which enhances local productivity (Fernandes et al., 2017). Thus, the total nitrogen $\left(\mathrm{NH}_{4}{ }^{+}, \mathrm{NO}_{2}{ }^{-}\right.$ and $\mathrm{NO}_{3}{ }^{-}$) concentration (subsequently "nutrients") in the water was measured in the laboratory (following the methods of Strickland and Parsons, 1972) from samples taken weekly in triplicates from superficial water from 20 days prior to the experiment starting and throughout the experimental period to evaluate the effect of natural eutrophication on benthic cover. Water temperature was measured at 6-hourly intervals during the experimental period using a data logger (Tidbit v2 Onset $\mathrm{HOBO}$, accuracy of $\pm 0.21^{\circ} \mathrm{C}$ from $0^{\circ}$ to $50^{\circ} \mathrm{C}$, calibrated by manufacturer) installed (at $4 \mathrm{~m}$ deep), near the experiments and used as a second proxy of upwelling effects.

\section{Exclusion Experiments}

The experiment was set up in November 2012 and monitored until June 2013, ending after 205 days. Eighty experimental 


\section{A}

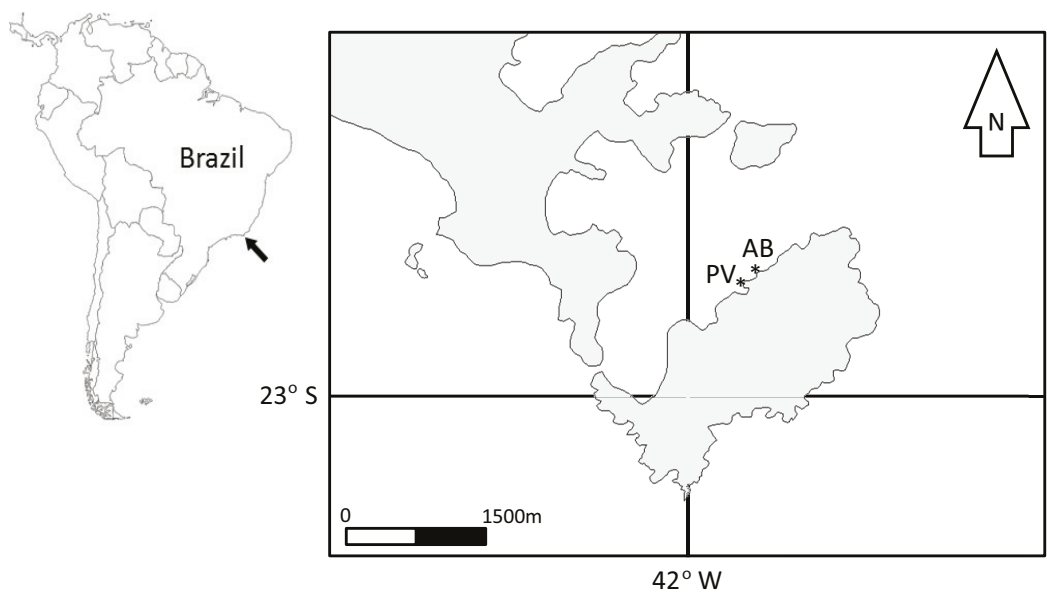

B

\section{Site}

Depth

Treatment

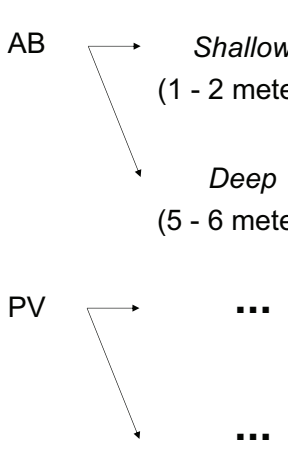

FIGURE 1 | (A) Map of Arraial do Cabo region (RJ, Brazil). The asterisks in the figure on the right show the experimental sites. (B) Experimental design schema indicating levels of factors, treatments and replication applied-images of treatments are available in the Supplementary $\mathbf{M a t e r i a l . ~} \mathrm{AB}-\mathrm{Abobrinha}\left(22.985^{\circ} \mathrm{S}\right.$, $\left.41.991^{\circ} \mathrm{W}\right), \mathrm{PV}-$ Pedra Vermelha $\left(22.986^{\circ} \mathrm{S},-41.993^{\circ} \mathrm{W}\right)$

plots were assigned to 20 blocks equally divided between two neighboring sites (Figure 1) at two different depth strata: shallow (1-2 $\mathrm{m}$ ) and deep (5-6 m). At each depth, 10 experimental blocks were composed of replicate patches $(25 \mathrm{~cm} \times 25 \mathrm{~cm})$ of benthos, which were assigned to three treatments and a control (open plot). The treatments consisted of a fence only (excluding grazing by sea urchins), a roof only (excluding grazing by fishes $>10 \mathrm{~cm}$ ), and a full cage (excluding grazing by fishes and sea urchins). Experimental structures were made of stainless steel (mesh size of $0.5 \mathrm{~cm}$ ) with dimensions of $25 \mathrm{~cm} \times 25 \mathrm{~cm} \times 7 \mathrm{~cm}$, except the rooves. The roof structures were made of a polyethylene net with mesh size of $2 \mathrm{~cm}$ to keep similar light conditions for all treatments. All structures were anchored to the substratum using cable ties to screws fixed with epoxy resin for underwater use $\left(\right.$ Tubolit $\left.^{\circledR}\right)$ at the four corners.

Treatments were visited every 5-7 days for cleaning or repairing of structures when necessary. The substrate cover inside treatments was recorded at least fortnightly through digital photography, totaling 16 samples of each replicate patch. These images were analyzed with CPCe software (v3.6), using 50 random points for each image of $20 \mathrm{~cm} \times 20 \mathrm{~cm}$ (the outer $5 \mathrm{~cm}$ border of images was excluded from analyzed frames to avoid any edge effects). Substrate cover was determined for each of the points at the lowest possible taxonomical level, then grouped for analysis into morpho-functional groups (Table 1) based on Littler and Littler (1984), Steneck and Dethier (1994) and Ferreira and Gonçalves (2006). The optimal number of points to be sampled was calculated based on the asymptote of substrate cover diversity curves (Lucas, 2013).

\section{Data Analysis}

Second-stage NMDS was applied to transformed (arcsin square root) cover data of all observed benthic groups to identify the effect of experimental treatments on assemblage structure over time. The Euclidean distance between replicates of treatments based on the arcsine square-rooted transformed cover was 
TABLE 1 | Comparative results of PERMANOVA for substrate cover composition and dominant groups among treatments, depth strata and site at Arraial do Cabo (RJ, Brazil) rocky reefs.

\begin{tabular}{|c|c|c|c|c|c|c|c|c|c|c|c|}
\hline \multirow[t]{2}{*}{ Treatments } & \multirow[t]{2}{*}{$d f$} & \multicolumn{2}{|c|}{ All cover groups } & \multicolumn{2}{|c|}{ Macroalgae } & \multicolumn{2}{|c|}{ CCA } & \multicolumn{2}{|c|}{ ACA } & \multicolumn{2}{|c|}{ EAM } \\
\hline & & Pseudo-F & $p$ & Pseudo-F & $p$ & Pseudo-F & $p$ & Pseudo-F & $p$ & Pseudo-F & $p$ \\
\hline Stratum (St) & 1 & 4.40 & $0.039^{\star}$ & 0.64 & 0.510 & 14.20 & 0.066 & 0.01 & 0.948 & 29.30 & $0.032^{\star}$ \\
\hline Site:Stratum (Si(St)) & 2 & 1.76 & 0.127 & 8.69 & $0.004^{*}$ & 0.42 & 0.683 & 3,87 & $0.048^{*}$ & 0.73 & 0.509 \\
\hline Between subjects error & 16 & - & - & - & - & - & - & - & - & - & - \\
\hline Total between & 19 & - & - & - & - & - & - & - & - & - & - \\
\hline Block:Site:Stratum & 16 & 1.13 & 0.293 & 0.59 & 0.869 & 0.94 & 0.541 & 1.73 & 0.072 & 0.89 & 0.577 \\
\hline Treatment (Tr) & 3 & 5.17 & 0.001 & 1.81 & 0.241 & 13.36 & $0.006^{*}$ & 1.55 & 0.279 & 6.42 & $0.025^{\star}$ \\
\hline Control $\times$ Cage $(\operatorname{Tr} 1)$ & 1 & 5.32 & $0.025^{\star}$ & 1.89 & 0.306 & 10.67 & 0.086 & 0.09 & 0.792 & 10.03 & 0.088 \\
\hline Control × Fence $(\operatorname{Tr} 2)$ & 1 & 9.25 & $0.004^{*}$ & 1.99 & 0.288 & 14.84 & 0.058 & 1.56 & 0.346 & 120.99 & $0.009^{*}$ \\
\hline Control × Roof $(\operatorname{Tr} 3)$ & 1 & 3.18 & 0.117 & 2.25 & 0.272 & 13.16 & 0.065 & 0.55 & 0.096 & 2.85 & 0.236 \\
\hline $\mathrm{Tr} \times \mathrm{St}$ & 3 & 5.64 & $0.001^{\star}$ & 1.18 & 0.383 & 14.02 & $0.005^{\star}$ & 11.69 & $0.008^{\star}$ & 5.13 & $0.043^{\star}$ \\
\hline St $\times \operatorname{Tr} 1$ & 1 & 8.09 & $0.005^{\star}$ & 0.32 & 0.629 & 27.62 & $0.035^{\star}$ & 7.14 & 0.121 & 15.14 & $0.054^{*}$ \\
\hline St $\times \operatorname{Tr} 2$ & 1 & 16.11 & $0.001^{\star}$ & 2.34 & 0.267 & 23.18 & $0.043^{\star}$ & 47.96 & $0.022^{\star}$ & 86.67 & $0.009^{*}$ \\
\hline St $\times \operatorname{Tr} 3$ & 1 & 0.98 & 0.491 & 0.35 & 0.618 & 1.93 & 0.305 & 1.00 & 0.419 & 0.73 & 0.486 \\
\hline $\operatorname{Tr} \times \mathrm{Si}(\mathrm{St})$ & 6 & 0.62 & 0.885 & 0.79 & 0.586 & 0.36 & 0.902 & 0.47 & 0.838 & 0.84 & 0.548 \\
\hline $\mathrm{Si}(\mathrm{St}) \times \operatorname{Tr} 1$ & 2 & 0.60 & 0.756 & 1.81 & 0.185 & 0.31 & 0.740 & 0.59 & 0.577 & 0.52 & 0.596 \\
\hline $\mathrm{Si}(\mathrm{St}) \times \operatorname{Tr} 2$ & 2 & 0.19 & 0.994 & 0.36 & 0.699 & 0.13 & 0.878 & 0.28 & 0.751 & 0.02 & 0.987 \\
\hline $\mathrm{Si}(\mathrm{St}) \times \operatorname{Tr} 3$ & 2 & 0.32 & 0.924 & 1.16 & 0.337 & 0.12 & 0.894 & 0.05 & 0.953 & 0.44 & 0.646 \\
\hline Within subjects error & 51 & - & - & - & - & - & - & - & - & - & - \\
\hline Total within & 79 & - & - & - & - & - & - & - & - & - & - \\
\hline
\end{tabular}

CCA, crustose coralline algae; ACA, articulate coralline algae; EAM, epilithic algal matrix. *significant value at $p<0.05$.

applied in the second-stage NMDS to create separate similarity matrices for each time step (i.e., sampling event). Samples of both sites were pooled in similarity matrices. After, all time step matrices of each treatment and depth stratum were compared for correlation (Spearman rank) separately. This analysis reduces the dimensionality of the corresponding coverage of the morphological and functional groups at each time interval into a centroid, and all subsequent comparison matrices into a single matrix diagram (Clarke and Warwick, 2001). The spatial variation of the centroids corresponding to each time unit indicates the trend of change in composition of the substrate cover through time, particularly indicating the presence of cyclic changes (Clarke et al., 2006).

Treatment effects on substrate cover composition was investigated using PERMANOVA (PRIMER-e v.6 software; Clarke and Gorley, 2006) applied to same transformed data, with resemblance matrix obtained from Euclidean distance similarity. Comparisons of treatments were demonstrated by the contrasting effects of fence, roof and the combination of these two (i.e., cages) against controls. Hypothetically, if both groups of herbivores contributed equally to grazing, we would expect a higher dissimilarity between the full exclusion treatment and the controls than between the partial treatments and controls (i.e., Cages $\neq$ Roof $=$ Fence $\neq$ Control). Another potential outcome is different effects of herbivorous fishes (Cages $=$ Roof $\neq$ Fence $\sim$ Control) or sea urchins (Cages $=$ Fence $\neq$ Roof $\sim$ Control). Other combinations would be probably linked to unmeasured factors or inefficacity of treatment devices (Underwood, 1996).

All analyses were conducted considering block as a random factor nested in site and depth strata, with treatment (four levels) and depth (two levels) as fixed crossed factors. Analyses followed the protocol proposed by Anderson et al. (2016) with a two-step procedure, first analyzing the within-subjects variation and then among-subjects variation, in order to best separate the possible effects of unreplicated levels (i.e., blocks). Additionally, to help evaluate variation associated with tested variables, confidence intervals of means for each treatment were calculated together with the effect size (Cohen's $d$ ) for nested designs using control plots as the 'control arm' following Lai and Kwok (2016).

The relative cover of dominant morpho-functional groups ( $>10 \%$ of total cover, i.e., EAM, crustose coralline algae - CCA, macroalgae and ACA) was compared among treatments and controls using univariate permutational ANOVA in PRIMER (Clarke and Gorley, 2006), following the same rationale applied for the whole benthic community.

The mean relative cover of dominant morpho-functional groups, nutrients concentration, and temperature data were tested for cross-correlation to examine possible cyclical interactions. No significant autocorrelation or cross-correlation was found between nutrients or temperature and morphofunctional groups tested (Supplementary Figures S1, S2). Nutrients and temperature were incorporated into the analysis with a lag of 2 weeks, as indicated by the result of cross-correlation analysis between these variables (ACF lag $2=-0.58$, see Supplementary Figure S1). Associations between abiotic variables (i.e., nutrients and water temperature) and the influence of time in substrate cover were investigated using dbRDA (distance-based redundancy analysis) following Anderson et al. (2016). Depth and site were included in the dbRDA as dummy variables, and only data from control plots 
was used in those analyses in order to avoid confounding effects from temporal dependency and exclusion treatment effects. To evaluate the significance of axes and variables to dbRDA models a permutation-based tests was applied (Legendre et al., 2011). Ordination analyses were performed using vegan package (Oksanen et al., 2019) from R software (R Core Team, 2019).

\section{RESULTS}

In total, 42 taxa were identified within six benthic morphofunctional groups (Supplementary Table S1). Considering the sampling period, structurally less complex morpho-functional algae taxa were found at shallow settings. Corallinaceae $(46.6 \% \pm 0.9$ s.e. of total cover) and epilithic algal matrix $(25.4 \% \pm 0.9)$ were the most abundant in the shallow stratum, while macroalgae $(42.1 \% \pm 1.1)$ and EAM $(32.7 \% \pm 0.9)$ were the predominant benthic morpho-functional groups in the deep stratum. The upwelling season showed higher variation in nutrients $(1-4 \mu \mathrm{M})$ and temperatures $\left(15-25^{\circ} \mathrm{C}\right)$, while the non-upwelling season was characterized by warmer and more stable water temperatures $\left(\sim 23^{\circ} \mathrm{C}\right)$ and less variable nutrients concentration $(\sim 1 \mu \mathrm{M})$ (Figure 2).

The general composition of benthic cover oscillated through time and among treatments indicating some temporal trends in benthic composition (Figure 3). These ordinations were the best bidimensional representation of a multivariate space, and the interpretation of those is here treated as guidance for observed general patterns of benthic communities through time, depth and treatments. The composition of benthic groups of total exclusion (i.e., cages) treatments at both depths, and sea urchin exclusion (i.e., fences) at the shallow stratum changed progressively (Figure 3), i.e., the position of first and last time steps are distant in the diagram and with few or non-crossing pathways. In contrast, a cyclical tendency was observed for all other treatments at shallow and deep settings, with the composition at the last time step of the experimental period returning to close to the composition at the first time step (Figure 3).

Plots not reached by both fishes and sea urchins (cages) and only accessible to fishes (fences) in the shallow stratum had an increase in complexity of morpho-functional group during the sampling period, switching from an initially bare stage dominated by crustose algae ( $>60 \%)$ to a low profile dominated by epilithic algae (EAM) (Figure 4). Open plots (controls) and plot accessible only to sea urchins (roof) had few changes in composition, remaining mostly covered by crustose algae (CCA) throughout the sampling period (Figure 4). These divergences in relative cover of morpho-functional groups were evident during the dry season (Figure 4). In contrast, macroalgae and articulated coralline algae (ACA) showed little variation through time and among treatments (Figure 4). Treatments excluding sea urchin and fishes, and only sea urchins had higher values of crustose algae (CCA) during conditions of high nutrients (i.e., upwelling season), which steadily decreased during the non-upwelling season (Figure 4). However, in controls and fish exclusion only (roof) this increase in crustose algae was not observed during the upwelling season (Figure 4).
In the deep stratum, the macroalgal dominance ( $>90 \%$ Sargassum spp.) was clear during the upwelling season for all treatments and control (Figure 4). No noticeable differences could be observed in mean cover of the four tested algal groups at the deep stratum, and groups behave in the same fashion through time irrespective of treatment (Figure 4 and Table 1). The cover of epilithic algae (EAM) increased when temperature stabilized $\left(\sim 22^{\circ} \mathrm{C}\right)$, and nutrients concentration decreased $\left(<1 \mu \mathrm{m} \mathrm{N} \mathrm{N}_{2}\right)$ after approximately 100 days (Figures 2, 4). The mean cover of crustose algae (CCA) also increased throughout the experimental period (Figure 4), as a result of its higher detectability after the senescence of Sargassum by the end of upwelling season. Macroalgal cover was composed of foliose algae from the genera Dictyota and Dictyopteris at the end of the experimental period, and no Sargassum spp. was found at that time. Higher cover of articulated coralline algae (ACA) occurred at the very beginning and end of experimental period, associated with low nutrients conditions irrespective of temperature, in a complementary cycle to the macroalgal cover oscillation (Figure 4).

The cumulative changes in composition of substrate cover were reflected in differences between depths and treatments, but no effect for site or interaction between site and treatment (Table 1). No effect was associated with variance within subjects (i.e., blocks) indicating that the lack of replication at the lowest level did not influence the overall analysis. An interaction between treatment and depth was observed for contrasts between control and cage, and control and fence, indicating no effects of the roof treatment (Table 1) on benthic composition, i.e., any effect of grazing by fishes on benthic cover. The same interactions mirrored the large differences in composition between depths, which were also observed inside treatments by the end of the experiment (Table 1 and Figure 3) and reinforced by the lack of separation of deep treatments. The differences among shallow treatments can be attributed to the dominance of crustose algae in control and fish exclusion only treatments, and epilithic algae in sea urchin only and both grazers exclusions, i.e., fences and cages (Figure 4 and Table 1). Differences between study sites were only found for macroalgae and articulated algae (ACA), where mean cover values were higher in Abobrinha than Pedra Vermelha for both algae groups (Supplementary Figure S4). The absence of detectable effects of grazers on benthic cover in the deep stratum is confirmed by the overlapping in confidence intervals of treatments and the low effect size of contrasts (Figure 5). The higher mean cover of articulated (ACA) and epilithic algae (EAM) cover observed for fence and cage in the shallow stratum, were also reflected in larger effect sizes (Figure 5). For crustose algae, the opposite was observed, with lower mean cover observed for sea urchins and both grazers exclusions, but also with larger effect sizes for these treatments in the shallow stratum (Figure 5).

The results of ordination analyses of benthic cover from control replicates showed that depth, site, temperature and time were significant factors, accounting for $46.8,12.4,2$, and $0.5 \%$ of the explained variance respectively, while nutrients was not significant (Table 2). Temperature and time had a small positive association (Figure 6 and Table 2), reflecting only cumulative changes in cover toward the end of the experimental period. The ordination shows a clear division of benthic composition between 

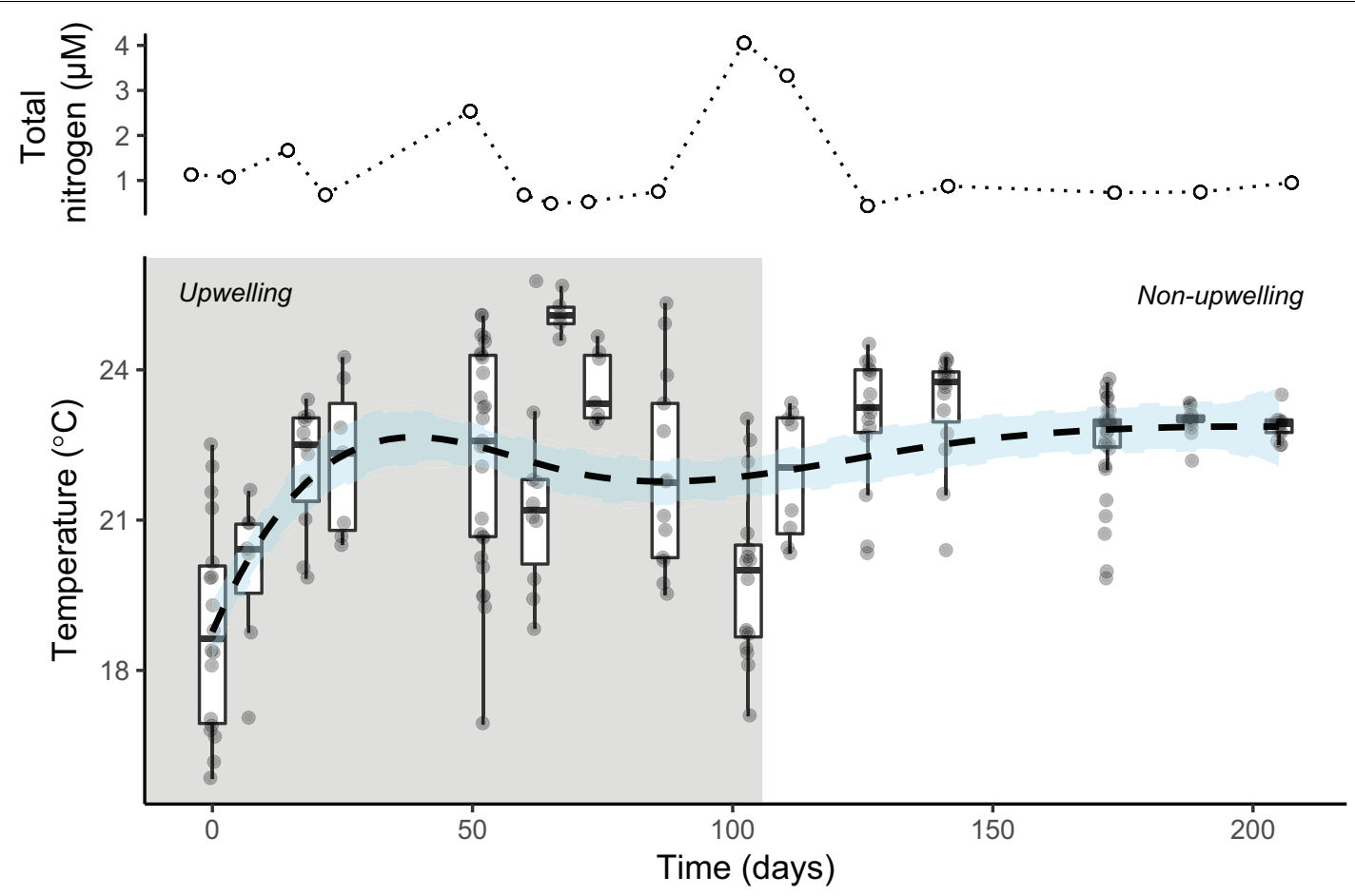

FIGURE 2 | Total nitrogen $\left(\mathrm{NH}_{4}{ }^{+}, \mathrm{NO}_{2}{ }^{-}\right.$and $\mathrm{NO}_{3}{ }^{-}$) concentration $(\mu \mathrm{M})$ and temperature variation (circles = samples, bar = median, box = 1st/3rd quartiles, and whiskers $=1.5 \times$ interquartile range) during experimental period of herbivore exclusion at Arraial do Cabo (RJ, Brazil). Shaded area indicates the period of higher variation in temperature (upwelling season). The dashed line ( \pm SE in light blue) indicated the smoothing spline estimates $(k=4)$ of mean temperature values. Values below $20^{\circ} \mathrm{C}$ are considered to be from South Atlantic Central Water masses, indicating upwelling events (Valentin, 1984).

depths, where crustose algae and substrate (mainly bare rock) were more associated with shallow areas, while macroalgae, EAM and sediment were located in the opposite side of the diagram, i.e., deep settings (Figure 6). Invertebrate cover and articulated algae (ACA) did not show associations with any explanatory variables, and differences between sites (Pedra Vermelha and Abobrinha) were not clearly observed in the ordination plot. In general, the patterns observed for average values of algal cover within treatments excluding sea urchins only (fence) and both grazers (cage) were reinforced by trends of effect sizes through time (Supplementary Figure S5). No trends were observed for algal groups irrespective of treatment in deeper water, while fence and cage had increasing effects over crustose and epilithic algae in shallower water.

\section{DISCUSSION}

Our exclusion experiment revealed that both biological and abiotic factors act in conjunction to structure benthic communities, with distinct effects related to depth on southwestern Atlantic rocky reefs. The influence of macroherbivores on algal dynamics was only significant at the shallow stratum $(1-2 \mathrm{~m})$, where sea urchins were the major consumers, with increasing cover of articulated (ACA) and epilithic algae (EAM) and decreasing crustose algae (CCA) in non-grazed treatments, which also increased the complexity of benthic cover. However, changes in nutrients and temperature may have buffered the grazing effects on benthic cover. Fluctuations of nutrients concentration and temperature seemed to be associated with substrate changes in treatments at both depths but were more evident on macroalgal cover in the deep stratum and associated with annual cycles, despite nutrients having no significant influence in ordination analyses. In contrast, in shallow sites, articulated (ACA) and epilithic algae (EAM) cover increased after the upwelling season, when nutrients concentrations were stable, and the mean temperature decreased, possibly associated with lower grazing activity of sea urchins (Ferreira, 1998). Higher and less variable mean temperatures in the late upwelling season appeared to have the opposite effect, and consequently increased CCA coverage within control and roof treatments.

The low macroalgal cover in the shallow stratum inside both cages and controls indicates that macroalgal occurrence is naturally low at that depth, possibly because of competition with other sessile groups, such as epilithic algae, articulated coralline algae and fire corals (Millepora alcicornis). Algal cover is also affected by depth gradients because of factors including light intensity and spectrum (Lubchenco, 1980; Carpenter, 1985) and wave action (Hurd, 2001). At shallower depths light incidence and wave action are more intense, which are better conditions for fast growing, dislodgement resistant, and low relief species of algae (Johansson and Snoeijs, 2002), 


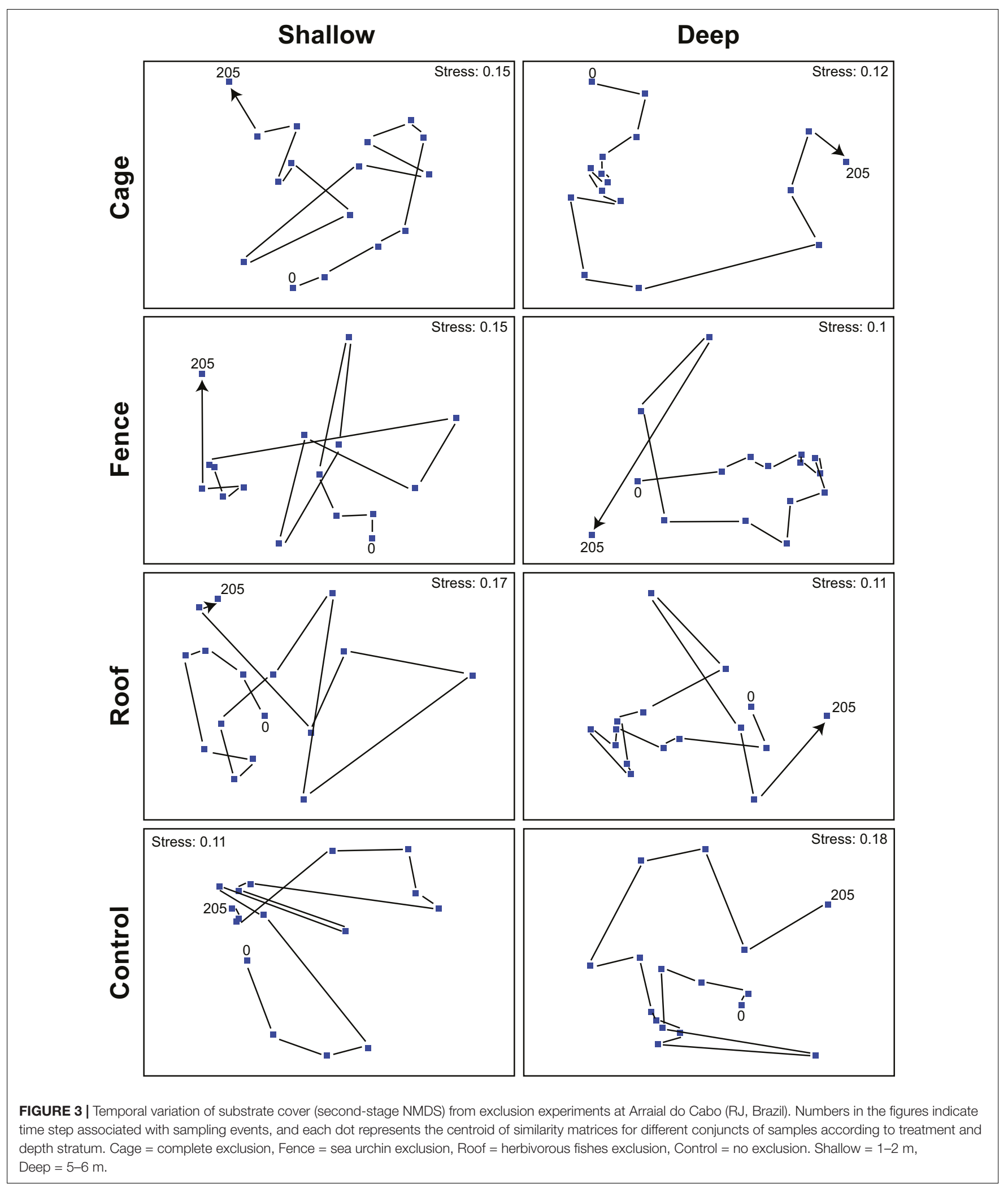

such as those found in EAM. Locally, macroalgae are either abundant at very shallow depths (intertidal to $<1 \mathrm{~m}$ depth, a habitat not assessed here) where physical factors (e.g., wave action, desiccation, and light inhibition) are more intense and prevent herbivory by macrograzers (Guimaraens and Coutinho, 1996), or below $5 \mathrm{~m}$. Temporal variation in algal coverage 

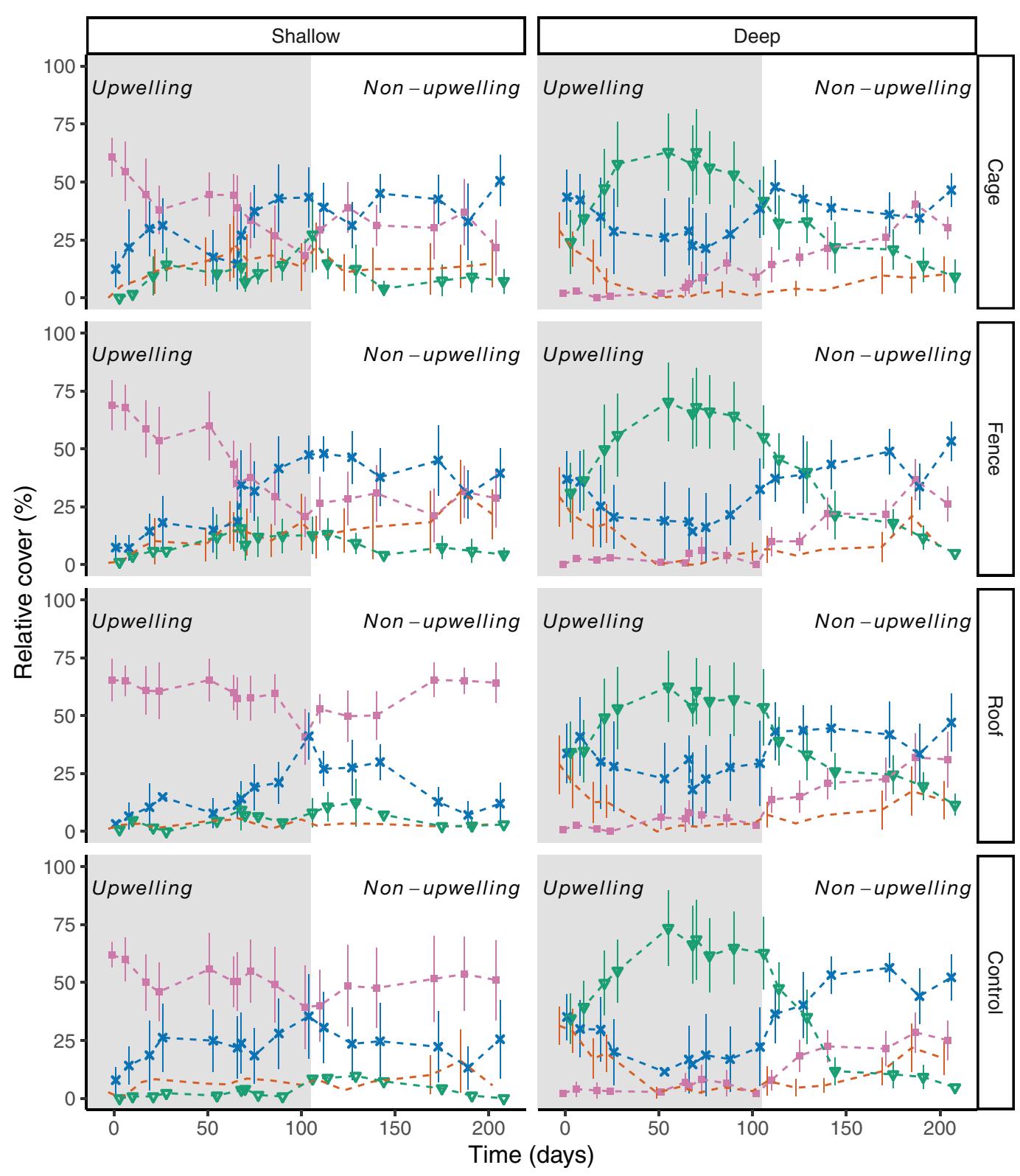

$-\phi-A C A-\phi-C C A-*-E A M-\downarrow-M A$

FIGURE 4 | Temporal variation in benthic cover (mean \pm SE) from shallow (1-2 m) and deep strata for herbivory exclusion and control treatments at Arraial do Cabo (RJ, Brazil). Shaded area indicates the period with higher temperature variation (upwelling season). MA = macroalgae, CCA = crustose coralline algae,

$\mathrm{ACA}=$ articulated coralline algae, EAM = epilithic algal matrix. Cage = complete exclusion, Fence = sea urchin exclusion, Roof = herbivorous fishes exclusion,

Control = no exclusion.

observed in the deeper stratum was homogeneous among all treatments, with some variation associated with EAM cover. Additionally, the temporal unimodal pattern of the macroalgal cover (mainly Sargassum furcatum) was related to variation of nutrients concentrations and low temperatures (i.e., upwelling events), indicating a stronger influence of abiotic than biotic factors (i.e., macro-herbivores grazing). The effects observed here captured in detail the transition at a typical subtropical reef site between upwelling and non-upwelling seasons covering the main oceanographic features within a climatic cycle. However, considering the importance of the upwelling to the benthic dynamics, further investigation considering multi-year and multi-location sampling would help deepen the understanding of the interannual differences and the effect of global or regional 


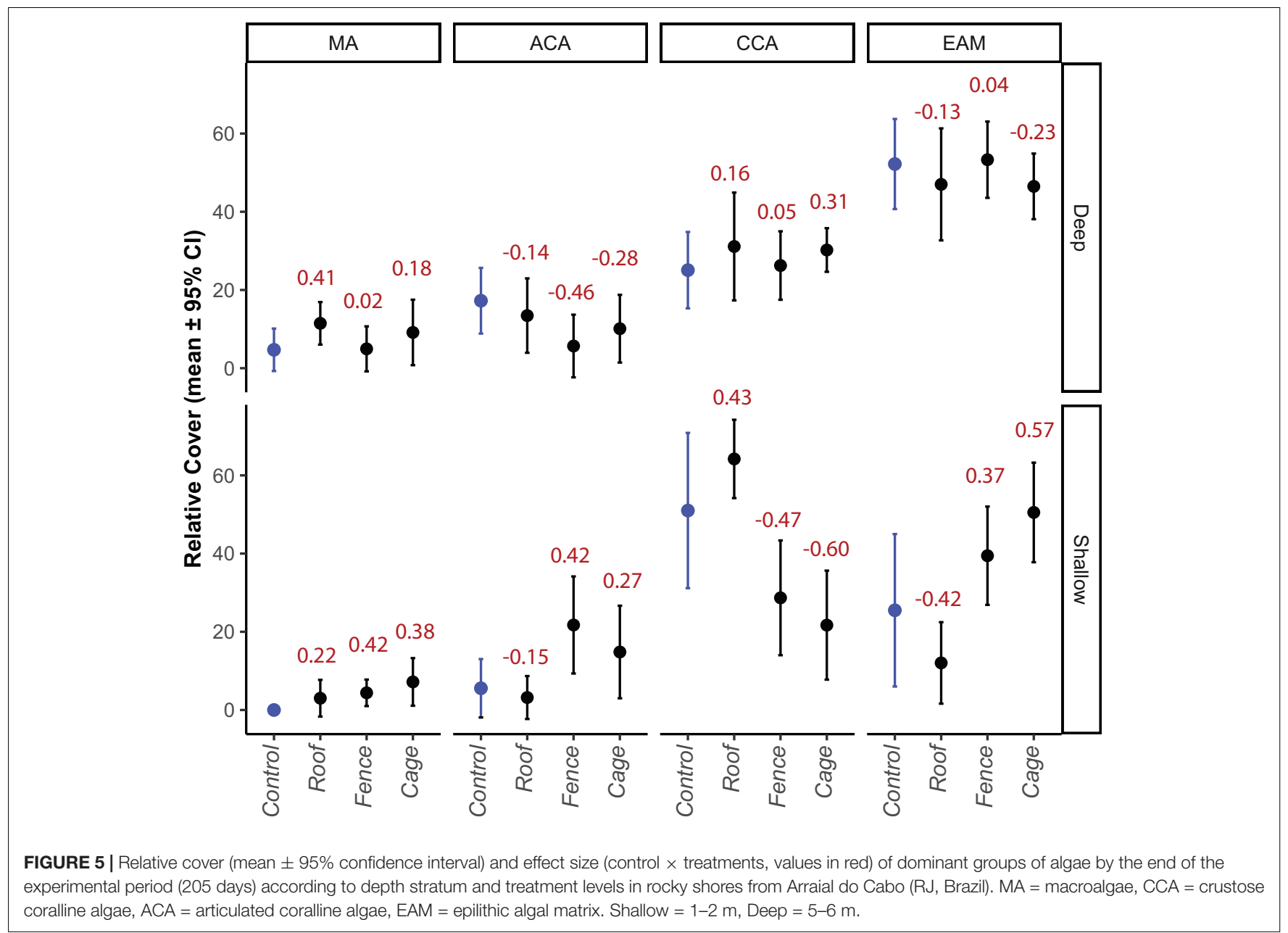

TABLE 2 | Results of redundancy analysis (dbRDA) showing (a) the eigenvalues and percentage of the overall variance explained by the first two axes, and (b) the relative contribution to constrained variance of tested variables.

\section{(a)}

\begin{tabular}{lcc}
\hline & Axis 1 & Axis 2 \\
\hline Eigenvalue & 2.49 & 0.72 \\
Proportion explained & 0.72 & 0.21 \\
\hline
\end{tabular}

(b)

\begin{tabular}{lcc}
\hline Variables & Adjusted explained variance & $\boldsymbol{p}$ value \\
\hline Depth & 0.468 & 0.001 \\
Site & 0.124 & 0.001 \\
Temperature & 0.021 & 0.009 \\
Time & 0.005 & 0.020 \\
Nutrients & $<0.001$ & 0.167 \\
\hline
\end{tabular}

Sum of eigenvalues for all axes $=3.44$.

climatic phenomena (e.g., ENSO, marine heatwaves) on the grazing pressure and macroalgae dynamics.

Sargassum occupies most of the subtidal rocky reefs in the study region during the upwelling season (October to
March) associated with upwelling nitrogen inputs (Coelho-Souza et al., 2012; Lanari and Coutinho, 2014) and decreases in cover during the non-upwelling season when upwelling events are less frequent, starting its senescence process (Guimaraens and Coutinho, 1996; Gonçalves, 1999). The cycle of other morpho-functional groups was in turn affected by shading and competition caused by Sargassum cycles and nutrients availability, such as foliose algae (e.g., Dictyota and Dictyopteris) that replaced Sargassum after senescence. Due to the twodimensional nature of images in the method applied, the canopy under Sargassum cover could not be easily detected, but CCA was observed throughout the experimental period at the deep stratum (CAMMC, personal observation). Sargassum overgrowth effects are only tolerated by CCA species that thrive under this dense canopy, due to their low light requirements (Leukart, 1994) and high abrasion resistance (Steneck and Dethier, 1994). Consequently, after the decrease in macroalgal cover, the high contribution of CCA was observed, followed by a gradual increase in the contribution of EAM and ACA, as would be expected in a natural process of succession for these algae (Ceccarelli et al., 2011).

The influence of the upwelling events on the composition and biomass of algal community at Arraial do Cabo region has 


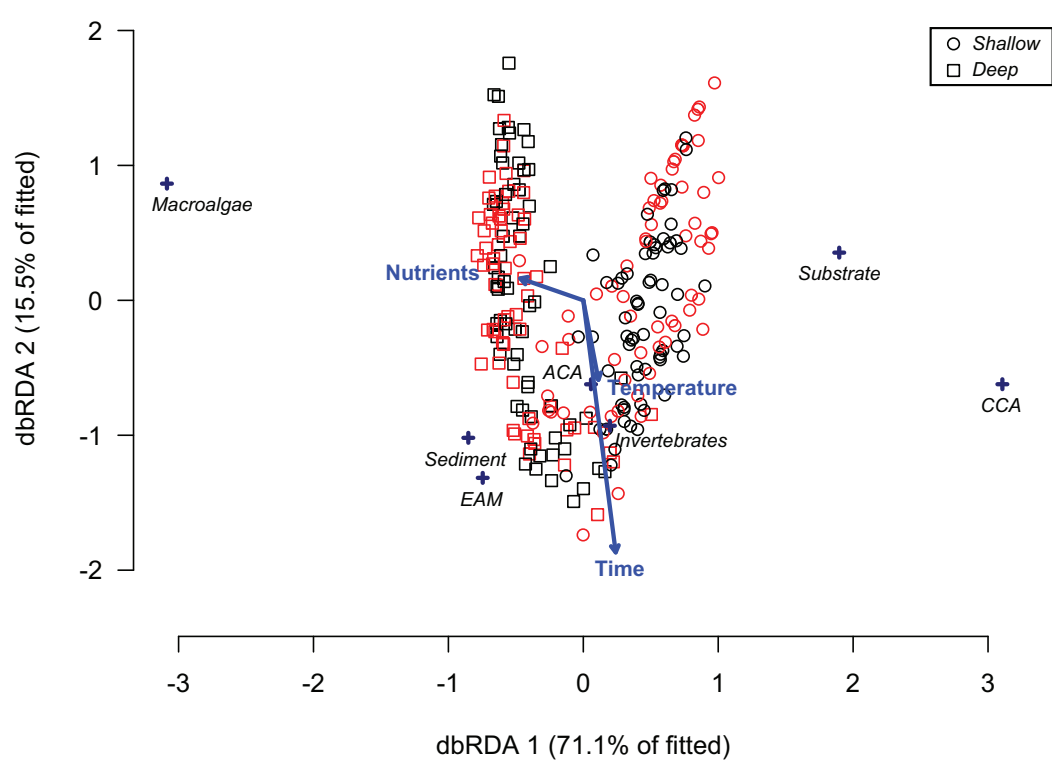

FIGURE 6 | Ordination biplot (distance-based redundancy analysis) of abiotic factors influencing the benthic cover of untouched plots (i.e., controls) in rocky shores from Arraial do Cabo (RJ, Brazil). CCA - crustose coralline algae. ACA - articulated coralline algae. EAM - epilithic algal matrix. The color of symbols indicates site origin, red $=$ Pedra Vermelha and black = Abobrinha. Shallow $=1-2 \mathrm{~m}$, Deep $=5-6 \mathrm{~m}$.

been described previously (Guimaraens and Coutinho, 1996; Lanari and Coutinho, 2014), indicating that nutrients variation (nitrate and ammonium) is crucial for spatial and temporal benthic dynamics. The natural levels of nitrogen compounds measured in this study were close to those observed at experiments applying artificial eutrophication treatments associated with herbivory exclusion (e.g., Diaz-Pulido and McCook, 2003; Sotka and Hay, 2009; Smith et al., 2010), and similar results (i.e., increase in macroalgae cover) were obtained under conditions of low herbivory and similar high nutrients concentrations (review in Littler and Littler, 2007). Thus, as nutrients are directly associated with temperature and benthic cover changes, the use of temperature as a proxy for future modeling of changes in benthic cover is suggested, given that monitoring temperature monitoring is typically cheaper and easier than for nutrients.

In shallow areas of subtropical reefs of Arraial do Cabo, a simultaneous increase in the net primary production (NPP) of epilithic algal matrix (early upwelling

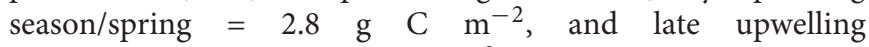
season/summer $=4.8 \mathrm{~g} \mathrm{C} \mathrm{m}^{-2}$, Ferreira, 1998) due to higher light and nutrients availability, and a decrease in consumption by herbivores (especially sea urchins) due to longer periods of low temperatures, can apparently generate a surplus of primary production. However, during the non-upwelling season, lower rates of EAM NPP (early upwelling season/autumn $=0.8 \mathrm{~g} \mathrm{C} \mathrm{m}^{-2}$, and late upwelling season/winter $=0.9 \mathrm{~g} \mathrm{C} \mathrm{m}^{-2}$, Ferreira, 1998) also reflected a reduction of macroalgae due to high consumption and low production. The effects observed here represent all four conditions predicted by the relative dominance model (RDM) (sensu Littler and Littler, 1984) for coral reefs, except that massive coral cover is naturally low when compared to tropical coral reefs (Oigman-Pszczol et al., 2004; Rogers et al., 2014). Firstly, under conditions of low nutrients and low herbivory, the algal community will be dominated by epilithic algae, which was observed here for all deep treatments, and under urchin grazing and total exclusions (i.e., fence and cage) at shallow sites. The opposite was observed for controls and roof treatment in the shallow stratum, where the dominance of CCA would indicate high herbivory, and both high and low nutrients conditions according to the RDM. Lastly, the dominance of macroalgae during the upwelling season, fueled by the upwelling, reflected a scenario of relatively low herbivory effects associated with high nutrients availability.

Guild composition of herbivores, and particularly their diet and feeding mode, is crucial to understand how these species interact with, and influence, the benthic assemblages (Bonaldo et al., 2014; Mendes et al., 2015; Allgeier et al., 2017; Longo et al., 2019). Sea urchins and herbivorous fishes show wide variations in their foraging rates and feeding selectivity (O'Leary and McClanahan, 2010; Mendes et al., 2018), but sea urchins feed less selectively when compared to fish due to their scraper apparatus (Black et al., 1984), the Aristotle's lantern. Besides having low mobility that restricts their foraging area $\left(\sim 1 \mathrm{~m}^{2}\right.$; Carpenter, 1984), sea urchins are less selective with food items when at high densities ( above 10 ind $\mathrm{m}^{-2}$ ) and may act as functional excavators removing even encrusting coralline algae and carbonate structures (Benedetti-Cecchi et al., 1998, 1999). Scenarios with CCA dominance and low macroalgal cover 
attributed to sea urchins' grazing action at shallow depths were also observed in rocky reefs of Spain (Palacín et al., 1998), Italy (Bulleri et al., 1999), and Cabo Verde (Entrambasaguas et al., 2008). In addition, in temperate reefs, where urchins exert high herbivory pressure over EAM and drift algae, CCA dominance persists (Scheibling and Hatcher, 2001). However, on tropical coral reefs, this positive relationship between sea urchins and CCA is observed only at low densities of sea urchins. At high densities (>15 ind $\mathrm{m}^{-2}$ for Diadema antillarum), this relationship is negative because of limited food resources that leads to the bioerosion of CCA (O'Leary and McClanahan, 2010).

Biomass values account for both size and abundance of specimens (density is the most common metric in sea urchin studies, e.g., Palacín et al., 1998; Tuya et al., 2004b; Lessios, 2016), which is crucial when comparing populations that are not homogeneous in size structure, as reported for Arraial do Cabo (see Cordeiro et al., 2014). Few studies have considered the biomass of sea urchins as a variable on tropical reefs, especially in the Caribbean, despite this being the most robust metric for assessing effects of grazing (Suskiewicz and Johnson, 2017). Studies in East Africa coral reefs indicated biomass values between 50.1 to $609.5 \mathrm{~g} \mathrm{~m}^{-2}$ (Humphries et al., 2014) in areas where sea urchins showed significant control over macroalgal cover. Similar to these studies, in Arraial do Cabo, the genus Echinometra is considered as the dominant species, but other less abundant species (e.g., Lytechinus variegatus, Paracentrotus gaimardi, Arbacia lixula) contribute to total grazing pressure. Average biomass values for sea urchins observed in Arraial do Cabo (3.2-7.1 $\mathrm{g} \mathrm{m}^{-2}$ ) were lower than those observed at Kenyan reefs, and yet significant effects over substrate cover were observed. However, generalizations on the association of biomass values and algal cover should be inferred with caution because the effects of herbivores on benthic coverage are directly related to the balance between NPP (e.g., because of different temperatures) and consumption, which may be affected by species-specific grazing rates irrespective of similar biomass values.

Herbivorous fishes have higher foraging mobility when compared to sea urchins, being able to explore larger areas and allowing a greater selectivity of items (Ferreira and Gonçalves, 2006; Burkepile and Hay, 2011; Mendes et al., 2015). This high mobility tends to keep algae in an initial growth stage (Ferreira et al., 1998), while sea urchins maintain the substrate clean of complex groups of algae, usually leaving only encrusting coralline algae (Scheibling and Hatcher, 2001). The high mobility of roving herbivorous species also leads to spatially variable herbivory pressure throughout the foraging area (Sandin and McNamara, 2012). On tropical reefs, the grazing of most abundant nominally herbivorous fishes (i.e., Scarinae) is predicted to be restricted to a maximum of $\sim 30 \%$ of reef area (Mumby, 2006), although it is not clear whether this is also true for subtropical reefs. These factors, coupled with the high availability of EAM and its high turnover rate (Russ, 2003; Bonaldo and Bellwood, 2011), may limit the effect of herbivorous fishes on benthic cover in this study. For example, small-bodied parrotfish species (e.g., Sparisoma radians and Sparisoma tuiupiranga) may have been able to forage under roof structures, but they did not influence partial exclusion plots. The biomass of nominally herbivorous fishes in subtropical reefs is considerable when compared to other groups of fishes (Morais et al., 2017; Longo et al., 2019). It is likely that those fishes have an important function on subtropical reef food webs through the detritus cycle, but their control of benthic dynamics (at least at the scale of habitats analyzed) was limited when compared to the Caribbean, and yet to be compared with tropical reefs of Brazilian coast. Biomass values for herbivorous fishes reported for the Caribbean (2-17.1 $\mathrm{g} \mathrm{m}^{-2}$, Williams and Polunin, 2001; up to $36 \mathrm{~g} \mathrm{~m}^{-2}$, Suchley and Alvarez-Filip, 2017; 7 to $>71.1 \mathrm{~g} \mathrm{~m}^{-2}$, Kuempel and Altieri, 2017) were similar to those found at Arraial do Cabo, but the exclusion of herbivory by fishes did not significantly affect algal growth in the present study. These findings were contrary to the study's initial hypothesis, where fish would have a major role as grazers due to the tropical affinity of local biota. Instead, only sea urchins were found to significantly influence the benthic cover by their intense grazing. It is also hard to know whether the apparently limited top-down control of macroalgae by fishes in the studied subtropical reefs is natural or due to reduced local populations (i.e., overfishing, Floeter et al., 2006), as the biomass of parrotfishes has been drastically decreased in the last two decades (Bender et al., 2014). Thus, there is still need for precautionary management action for herbivorous fishes in reefs along the Brazilian coast, as their functional role is still poorly explored.

These are the first results of caging experiments on benthic succession available for subtropical reefs in the South Atlantic. Studies related to the biology and ecology of sea urchins are also scarce in the South Atlantic (Ventura et al., 2013), which is a significant data gap given the high abundance of these important functional herbivores in reef environments. Most populations of sea urchins are $r$ strategists and controlled by top-down mechanisms (Bonaviri et al., 2012), making these populations more susceptible to population outbreaks and mass mortality events, as observed for Diadema antillarum in the Caribbean (Lessios et al., 2001). Mass mortality events of sea urchins have been recorded at Arraial do Cabo associated with blooms of toxic dinoflagellates (Ferreira, 2006), and subsequent events have been observed occasionally in the region (personal observation), but little is known about the long-term consequences to local sea urchin populations. In addition, information about past conditions on Brazilian reefs is rare, not only including scenarios where herbivorous fishes had higher abundance and could exert a top-down control over macroalgae, but also where lower biomass of sea urchins (controlled by predation) would limit barren formation. Moreover, the primary effects of nutrients input (i.e., upwelling) and sea urchin grazing over benthic cover dynamics on these subtropical reefs may indicate more similarities with the functioning of temperate systems than tropical reefs, which is crucial information for local managers facing possible regime shifts.

\section{DATA AVAILABILITY STATEMENT}

The datasets generated for this study are available on request to the corresponding author. 


\section{AUTHOR CONTRIBUTIONS}

$\mathrm{CC}$ and $\mathrm{CF}$ contributed to the conception and design of the study. $\mathrm{CC}$ and $\mathrm{AH}$ performed the statistical analysis. CC wrote the first draft of the manuscript. All authors contributed to manuscript writing, revision, read and approved the submitted version.

\section{FUNDING}

This work was financially supported by Fundação "O Boticário" de Proteção à Natureza (Grant \#0898/20111), FAPERJ Fundação de Amparo à Pesquisa do Rio de Janeiro (Grant \#111.711/2012), and was financed in part by the Coordenação de Aperfeiçoamento de Pessoal de Nível Superior - Brasil (CAPES) - Finance Code 001 (scholarship grant - CC). CF is supported by $\mathrm{CNPq}$ and FAPERJ grants.

\section{REFERENCES}

Allgeier, J. E., Adam, T. C., and Burkepile, D. E. (2017). The importance of individual and species-level traits for trophic niches among herbivorous coral reef fishes. Proc. R. Soc. B 284:20170307. doi: 10.1098/rspb.2017.0307

Alvares, C. A., Stape, J. L., Sentelhas, P. C., Gonçalves, J. L. M., and Sparovek, G. (2013). Köppen's climate classification map for Brazil. Meteorol. Z. 22, 711-728. doi: 10.1127/0941-2948/2013/0507

Anderson, M. J., Goarley, R. N., and Clark, K. R. (2016). PERMANOVA+ for PRIMER: Guide to Software and Statistical Methods. Plymouth: PRIMER-E Ltd.

Arantes, R. C. M., Castro, C. B., Pires, D. O., and Seoane, J. C. S. (2009). Depth and water mass zonation and species associations of cold-water octocoral and stony coral communities in the southwestern Atlantic. Mar. Ecol. Prog. Ser. 397, 71-79. doi: 10.3354/meps08230

Bender, M. G., Machado, G. R., de Azevedo Silva, P. J., Floeter, S. R., MonteiroNeto, C., Luiz, O. J., et al. (2014). Local ecological knowledge and scientific data reveal overexploitation by multigear artisanal fisheries in the Southwestern Atlantic. PLoS One 9:e110332. doi: 10.1371/journal.pone.0110332

Benedetti-Cecchi, L., Bulleri, F., and Cinelli, F. (1998). Density dependent foraging of sea urchins in shallow subtidal reefs on the west coast of Italy (western Mediterranean). Mar. Ecol. Prog. Ser. 163, 203-211. doi: 10.3354/meps16 3203

Benedetti-Cecchi, L., Menconi, M., and Cinelli, F. (1999). Pre-emption of the substratum and the maintenance of spatial pattern on a rocky shore in the northwest Mediterranean. Mar. Ecol. Progr. Ser. 181, 13-23. doi: 10.3354/ meps 181013

Bennett, S., and Bellwood, D. R. (2011). Latitudinal variation in macroalgal consumption by fishes on the Great Barrier Reef. Mar. Ecol. Prog. Ser. 426, 241-252. doi: 10.3354/meps09016

Black, R., Codd, C., Hebbert, D., Vink, S., and Burt, J. (1984). The functional significance of the relative size of Aristotle's lantern in the sea urchin Echinometra mathaei (de Blainville). J. Exp. Mar. Biol. Ecol. 77, 81-97. doi: 10.1016/0022-0981(84)90052-2

Bonaldo, R. M., and Bellwood, D. R. (2011). Spatial variation in the effects of grazing on epilithic algal turfs on the Great Barrier Reef, Australia. Coral Reefs 30, 381-390. doi: 10.1007/s00338-010-0704-4

Bonaldo, R. M., Hoey, A., and Bellwood, D. R. (2014). The ecosystem roles of parrotfishes on tropical reefs. Oceanogr. Mar. Biol. Annu. Rev. 81-132. doi: 10.1201/b17143-3

Bonaviri, C., Gianguzza, P., Pipitone, C., and Hereu, B. (2012). Micropredation on sea urchins as a potential stabilizing process for rocky reefs. J. Sea Res. 73, 18-23. doi: 10.1016/j.seares.2012.06.003

Bozec, Y.-M., and Mumby, P. J. (2015). Synergistic impacts of global warming on the resilience of coral reefs. Phil. Trans. R. Soc. B 370:20130267. doi: 10.1098/ rstb.2013.0267

Bulleri, F., Benedetti-Cecchi, L., and Cinelli, F. (1999). Grazing by the sea urchins Arbacia lixula L. and Paracentrotus lividus Lam. in the Northwest

\section{ACKNOWLEDGMENTS}

The authors are grateful to M. B. Lucena, L. Borde, B. Masi, M. C. Barbosa, and T. C. Mendes for the dedication and assistance in fieldwork. Also, the authors would like to thank C. J. Brown and J. C. Ortiz for helping with statistical analysis. This is contribution \#198 from the Coastlines and Oceans Division in the Institute for Environment at Florida International University.

\section{SUPPLEMENTARY MATERIAL}

The Supplementary Material for this article can be found online at: https://www.frontiersin.org/articles/10.3389/fmars. 2020.00488/full\#supplementary-material

Mediterranean. J. Exp. Mar. Biol. Ecol. 241, 81-95. doi: 10.1016/s0022-0981(99) 00073-8

Burkepile, D. E., and Hay, M. E. (2006). Herbivore vs nutrient control of marine primary producers: context dependent effects. Ecology 87, 3128-3139. doi: 10.1890/0012-9658(2006)87[3128:hvncom]2.0.co;2

Burkepile, D. E., and Hay, M. E. (2011). Feeding complementarity versus redundancy among herbivorous fishes on a Caribbean reef. Coral Reefs 30, 351-362. doi: 10.1007/s00338-011-0726-6

Carpenter, R. C. (1984). Predator and population density control of homing behavior in the Caribbean echinoid Diadema antillarum. Mar. Biol. 82, 101108. doi: $10.1007 / \mathrm{bf} 00392768$

Carpenter, R. C. (1985). Relationships between primary production and irradiance in coral reef algal communities. Limnol. Oceanogr. 30, 784-793. doi: 10.4319/ lo.1985.30.4.0784

Ceccarelli, D. M., Jones, G. P., and Mccook, L. J. (2011). Interactions between herbivorous fish guilds and their influence on algal succession on a coastal coral reef. J. Exp. Mar. Biol. Ecol. 399, 60-67. doi: 10.1016/j.jembe.2011.01.019

Clarke, K. R., and Gorley, R. N. (2006). PRIMER v6: User Manual/Tutorial. Plymouth: PRIMER-E, 192.

Clarke, K. R., Somerfield, P. J., Airoldi, L., and Warwick, R. M. (2006). Exploring interactions by second-stage community analyses. J. Exp. Mar. Biol. Ecol. 338, 179-192. doi: 10.1016/j.jembe.2006.06.019

Clarke, K. R., and Warwick, R. M. (2001). Change in Marine Communities: An Approach to Statistical Analysis and Interpretation, 2nd Edn. Plymouth: PRIMER-E.

Coelho-Souza, S. A., López, M. S., Guimarães, J. R. D., Coutinho, R., and Candella, R. N. (2012). Biophysical interactions in the Cabo Frio upwelling system, Southeastern Brazil. Braz. J. Oceanogr. 60, 353-365. doi: 10.1590/s167987592012000300008

Cordeiro, C. A. M. M., Harborne, A. R., and Ferreira, C. E. L. (2014). Patterns of distribution and composition of sea urchin assemblages on Brazilian subtropical rocky reefs. Mar. Biol. 166, 2221-2232. doi: 10.1007/s00227-014-2500-0

Cordeiro, C. A. M. M., Mendes, T. C., Harborne, A. R., and Ferreira, C. E. L. (2016). Spatial distribution of nominally herbivorous fishes across environmental gradients on Brazilian rocky reefs. J. Fish Biol. 89, 939-958. doi: 10.1111/jfb. 12849

D'Angelo, C., and Wiedermann, J. (2014). Impacts of nutrient enrichment on coral reefs: new perspectives and implications for coastal management and reef survival. Curr. Opin. Environ. Sustainabil. 7, 82-93. doi: 10.1016/j.cosust.2013. 11.029

De Léo, F. C., and Pires-Vanin, A. M. S. (2006). Benthic megafauna communities under the influence of the South Atlantic Central Water intrusion onto the Brazilian SE shelf: a comparison between an upwelling and a non-upwelling ecosystem. J. Mar. Syst. 60, 268-284. doi: 10.1016/j.jmarsys.2006.02.002

Diaz-Pulido, G., and McCook, L. J. (2003). Relative roles of herbivory and nutrients in the recruitment of coral-reef seaweeds. Ecology 84, 2026-2033. doi: 10.1890/ 01-3127 
Entrambasaguas, L., Pérez-Ruzafa, A., Gárcia-Charton, J., Stobart, B., and Bacallado, J. J. (2008). Abundance, spatial distribution and habitat relationships of echinoderms in the Cabo Verde Archipelago (eastern Atlantic). Mar. Freshw. Res. 59, 477-488.

Estes, J. A., and Palmisano, J. F. (1974). Sea otters: their role in structuring nearshore communities. Science 185, 1058-1060. doi: 10.1126/science.185. 4156.1058

Fernandes, L. D. D. A., Fagundes Netto, E. B., Coutinho, R., and on behalf of the Peld-Reca (2017). Inter-annual cascade effect on marine food web: a benthic pathway lagging nutrient supply to pelagic fish stock. PLoS One 12:e184512. doi: 10.1371/journal.pone.0184512

Ferreira, C. E. L. (1998). Partilha de Recursos Por Herbívoros em um Costão Rochoso Tropical, Arraial do Cabo. PhD dissertation, Universidade Federal de São Carlos, São Carlos.

Ferreira, C. E. L. (2006). Sea urchin killed by toxic algae. J. Mar. Biol. Assoc. U.K. 3, 22-23.

Ferreira, C. E. L., and Gonçalves, J. E. A. (2006). Community structure and diet of roving herbivorous reef fishes in the Abrolhos archipelago, south-western Atlantic. J. Fish. Biol. 69, 1533-1551. doi: 10.1111/j.1095-8649.2006.01220.x

Ferreira, C. E. L., Gonçalves, J. E. A., Coutinho, R., and Peret, A. C. (1998). Herbivory by the Dusky Damselfish Stegastes fuscus (Cuvier, 1830) in a tropical rocky shore: effects on the benthic community. J. Exp. Mar. Biol. Ecol. 229, 241-264. doi: 10.1016/s0022-0981(98)00056-2

Floeter, S. R., Halpern, B. S., and Ferreira, C. E. L. (2006). Effects of fishing protection on Brazilian reef fishes. Biol. Conserv. 128, 391-402. doi: 10.1016/ j.biocon.2005.10.005

Gonçalves, J. E. A. (1999). Influência da temperatura, luz e nutrientes ( $N$ e P) na dinâmica populacional de Sargassum furcatum Kuetzing (Phaeophyta: Fucales) na Ilha de Cabo Frio, Arraial do Cabo, RJ. Masters dissertation, Universidade Federal do Rio de Janeiro, Rio de Janeiro.

Guimaraens, M. A., and Coutinho, R. (1996). Spatial and temporal variation of benthic marine algae at the Cabo Frio upwelling region, Rio de Janeiro, Brazil. Aquat. Bot. 52, 283-299. doi: 10.1016/0304-3770(95)00511-0

Horn, M. H. (1989). Biology of marine herbivorous fishes. Oceanogr. Mar. Biol. Annu. Rev. 27, 167-272.

Humphries, A. T., McClanahan, T. R., and McQuaid, C. D. (2014). Differential impacts of coral reef herbivores on algal succession in Kenya. Mar. Ecol. Prog. Ser. 504, 119-132. doi: 10.3354/meps 10744

Hurd, C. L. (2001). Water motion, marine macroalgal physiology, and production. J. Phycol. 36, 453-472. doi: 10.1046/j.1529-8817.2000.99139.x

INMET (2020). Instituto Nacional de Meteorologia - INMET (Brazilian Meteorological Institute). Available at www.inmet.gov.br (accessed April 2, 2020).

Johansson, G., and Snoeijs, P. (2002). Macroalgal photosynthetic responses to light in relation to thallus morphology and depth zonation. Mar. Ecol. Prog. Ser. 244, 63-72. doi: 10.3354/meps244063

Kriegisch, N., Reeves, S., Johnson, C. R., and Ling, S. D. (2016). Phase-shift dynamics of sea urchin overgrazing on Nutrified Reefs. PLoS One 11:e0168333. doi: 10.1371/journal.pone.0168333

Kuempel, C. D., and Altieri, A. H. (2017). The emergent role of small-bodied herbivores in pre-empting phase shifts on degraded coral reefs. Sci. Rep. 7:39670.

Lai, M. H. C., and Kwok, O.-M. (2016). Estimating standardized effect sizes for two- and three-level partially nested data. Multivar. Behav. Res. 51, 740-756. doi: 10.1080/00273171.2016.1231606

Lanari, M. O., and Coutinho, R. (2014). Reciprocal causality between marine macroalgal diversity and productivity in an upwelling area. Oikos 123, 630-640. doi: 10.1111/j.1600-0706.2013.00952.x

Legendre, P., Oksanen, J., and ter Braak, C. J. F. (2011). Testing the significance of canonical axes in redundancy analysis. Methods Ecol. Evol. 2, 269-277. doi: 10.1111/j.2041-210x.2010.00078.x

Lessios, H. A. (2016). The great Diadema antillarum die-off: 30 years later. Annu. Rev. Mar. Sci. 8, 267-283.

Lessios, H. A., Garrido, M. J., and Kessing, B. D. (2001). Demographic history of Diadema antillarum a keystone herbivore on Caribbean reefs. Proc. R. Soc. Lond. B 268, 2347-2353. doi: 10.1098/rspb.2001.1806

Leukart, P. (1994). Field and laboratory studies on depth dependence, seasonality and light requirement of growth in three species of crustose coralline algae
(Corallinales, Rhodophyta). Phycologia 33, 281-290. doi: 10.2216/i0031-888433-4-281.1

Littler, M. M., and Littler, D. S. (1984). "A relative-dominance model for biotic reefs. in advances in reef sciences," in Proceedings of the Joint Meeting of the Atlantic Reef Committee and the International Society of Reef Studies, Miami, FL.

Littler, M. M., and Littler, D. S. (2007). Assessment of coral reefs using herbivory/nutrient assays and indicator groups of benthic primary producers: a critical synthesis, proposed protocols, and critique of management strategies. Aquat. Conserv. Mar. Freshw. Ecosyst. 17, 195-215. doi: 10.1002/aqc.790

Longo, G. O., Hay, M. E., Ferreira, C. E. L., and Floeter, S. R. (2019). Trophic interactions across 61 degrees of latitude in the Western Atlantic. Glob. Ecol. Biogeogr. 28, 107-117. doi: 10.1111/geb.12806

Lubchenco, J. (1980). Algal zonation in the New England rocky intertidal community: an experimental analysis. Ecology 61, 333-344. doi: 10.2307/ 1935192

Lubchenco, J., and Gaines, S. D. (1981). A unified approach to marine plantherbivore interactions. I. Populations and communities. Annu. Rev. Ecol. Evol. Syst. 12, 405-437. doi: 10.1146/annurev.es.12.110181.002201

Lucas, M. M. F. (2013). Análise dos padrões de cobertura recifal em costões rochosos de Arraial do Cabo, RJ. Honors dissertation, Universidade Federal Fluminense, Niterói, RJ.

Mazzuco, A. C. A., Christofoletti, R. A., Coutinho, R., and Ciotti, ÁM. (2018). The influence of atmospheric cold fronts on larval supply and settlement of intertidal invertebrates: case studies in the Cabo Frio coastal upwelling system (SE Brazil). J. Sea Res. 137, 47-56. doi: 10.1016/j.seares.2018.02.010

Mendes, T. C., Cordeiro, C. A. M. M., and Ferreira, C. E. L. (2015). An experimental evaluation of macroalgal consumption and selectivity by nominally herbivorous fishes on subtropical rocky reefs. J. Exp. Mar. Biol. Ecol. 471, 146-152. doi: 10.1016/j.jembe.2015.06.001

Mendes, T. C., Ferreira, C. E. L., and Clements, K. D. (2018). Discordance between diet analysis and dietary macronutrient content in four nominally herbivorous fishes from the Southwestern Atlantic. Mar. Biol. 165:180. doi: 10.1007/s00227018-3438-4

Morais, R. A., Ferreira, C. E. L., and Floeter, S. R. (2017). Spatial patterns of fish standing biomass across Brazilian reefs, Southwestern Atlantic. J. Fish Biol. 91, 1642-1667.doi: 10.1111/jfb.13482

Mumby, P. J. (2006). The impact of exploiting grazers (Scaridae) on the dynamics of Caribbean coral reefs. Ecol. Appl. 16, 747-769. doi: 10.1890/1051-0761(2006) 016[0747:tioegs]2.0.co;2

Mumby, P. J., Dahlgren, C. P., Harborne, A. R., Kappel, C. V., Micheli, F., Brumbaugh, D. R., et al. (2006). Fishing, trophic cascades, and the process of grazing on coral reefs. Science 311, 98-101. doi: 10.1126/science.1121129

Mumby, P. J., and Hastings, A. (2008). The impact of ecosystem connectivity on coral reef resilience. J. Appl. Ecol. 45, 854-862. doi: 10.1111/j.1365-2664.2008. 01459.x

Nogueira-Júnior, M., and Brandini, F. (2018). "Community structure and spatiotemporal dynamics of the zooplankton in the South Brazilian Bight: a review," in Plankton Ecology of the Southwestern Atlantic, ed. M. S. Hoffmeyer (Switzerland: Springer International Publishing), 149-179.

Oigman-Pszczol, S. S., Figueiredo, M. A. O., and Creed, J. C. (2004). Distribution of benthic communities on the tropical rocky subtidal of Armação dos Búzios, Southeastern Brazil. Mar. Ecol. 25, 173-190. doi: 10.1111/j.1439-0485.2004. 00018.x

Oksanen, J., Blanchet, F. G., Friendly, M., Kindt, R., Legendre, P., McGlinn, D., et al. (2019). vegan: Community Ecology Package. R package version 2.5-4.

O'Leary, J. K., and McClanahan, T. R. (2010). Trophic cascades result in large-scale coralline algae loss through differential grazer effects. Ecology 91, 3584-3597. doi: 10.1890/09-2059.1

Palacín, C., Giribet, G., and Carner, S. (1998). Low densities of sea urchins influence the structure of algal assemblages in the western Mediterranean. J. Sea Res. 39, 281-290. doi: 10.1016/s1385-1101(97)00061-0

Poore, A. G. B., Campbell, A. H., Coleman, R. A., Edgar, G. J., Jormalainen, V., Reynolds, P. L., et al. (2012). Global patterns in the impact of marine herbivores on benthic primary producers. Ecol. Lett. 15, 912-922. doi: 10.1111/j.14610248.2012.01804.x

R Core Team (2019). R: A Language and Environment for Statistical Computing. Vienna: R Foundation for Statistical Computing. 
Roff, G., Chollett, I., Doropoulos, C., Golbuu, Y., Steneck, R. S., Isechal, A. L., et al. (2015). Exposure-driven macroalgal phase shift following catastrophic disturbance on coral reefs. Coral Reefs 34, 715-725. doi: 10.1007/s00338-0151305-Z

Rogers, R., Correal, G. O., Cunha, T. C., Carvalho, L. L., Mazurek, P., Barbosa, M. A., et al. (2014). Coral health rapid assessment in marginal reef sites. Mar. Biol. Res. 10, 612-624.

Russ, G. R. (2003). Grazer biomass correlates more strongly with production than with biomass of algal turfs on a coral reef. Coral Reefs 22, 63-67. doi: 10.1007/ s00338-003-0286-5

Sala, E., and Boudouresque, E. (1997). The role of fishes in the organization of a Mediterranean sublittoral community. I: algal communities. J. Exp. Mar. Biol. Ecol. 212, 25-44. doi: 10.1016/s0022-0981(96)02745-1

Sandin, S. A., and McNamara, D. E. (2012). Spatial dynamics of benthic competition on coral reefs. Oecologia 168, 1079-1090. doi: 10.1007/s00442011-2156-0

Scheibling, R. E., and Hatcher, B. G. (2001). "The ecology of Strongylocentrotus droebachiensis," in Edible Sea Urchins - Biology and Ecology, ed. J. M. Lawrence (Amsterdam: Elsevier), 271-305.

Sellers, A. J., Leung, B., and Torchin, M. E. (2019). Global meta-analysis of how marine upwelling affects herbivory. Glob. Ecol. Biogeogr. 29, 370-383. doi: 10. 1111 /geb.13023

Sheppard-Brennand, H., Dworjanyn, S. A., and Poore, A. G. B. (2017). Global patterns in the effects of predator declines on sea urchins. Ecography 40, 1029-1039. doi: 10.1111/ecog.02380

Smith, J. E., Hunter, C. L., and Smith, C. M. (2010). The effects of top-down versus bottom-up control on benthic coral reef community structure. Oecologia 163, 497-507. doi: 10.1007/s00442-009-1546-z

Sotka, E. E., and Hay, M. E. (2009). Effects of herbivores, nutrient enrichment, and their interactions on macroalgal proliferation and coral growth. Coral Reefs 28, 555-568. doi: 10.1007/s00338-009-0529-1

Steneck, R. S., Bellwood, D. R., and Hay, M. E. (2017). Herbivory in the marine realm. Curr. Biol. 27, 484-488.

Steneck, R. S., and Dethier, M. N. (1994). A functional group approach to the structure of algal-dominated communities. Oikos 69, 476-498.

Strickland, J. D. H., and Parsons, T. R. (1972). A Practical Handbook of Seawater Analysis, 2nd Edn. Ottawa: Fisheries Research Board of Canada Bulletin.

Stuhldreier, I., Sánchez-Noguera, C., Roth, F., Jiménez, C., Rixen, T., Cortés, J., et al. (2016). Dynamics in benthic community composition and influencing factors in an upwelling-exposed coral reef on the Pacific coast of Costa Rica. PeerJ 3:e1434. doi: $10.7717 /$ peerj. 1434
Suchley, A., and Alvarez-Filip, L. (2017). Herbivory facilitates growth of a key reef-building Caribbean coral. Ecol. Evol. 7, 11246-11256. doi: 10.1002/ece3. 3620

Suskiewicz, T. S., and Johnson, L. E. (2017). Consumption rates of a key marine herbivore: a review of the extrinsic and intrinsic control of feeding in the green sea urchin. Mar. Biol. 164:131.

Tuya, F., Boyra, A., Sanchez-Jerez, P., Barbera, C., and Haroun, R. J. (2004a). Can one species determine the structure of the benthic community on a temperate rocky reef? The case of the long-spined sea-urchin Diadema antillarum (Echinodermata: Echinoidea) in the eastern Atlantic. Hydrobiologia 519, $211-$ 214. doi: 10.1023/b:hydr.0000026599.57603.bf

Tuya, F., Boyra, A., Sanchez-Jerez, P., Barbera, C., and Haroun, R. J. (2004b). Relationships between rocky-reef fish assemblages, the sea urchin Diadema antillarum and macroalgae throughout the Canarian Archipelago. Mar. Ecol. Prog. Ser. 278, 157-169. doi: 10.3354/meps278157

Underwood, A. J. (1996). Experiments in Ecology: Their Logical Design and Interpretation using Analysis of Variance. Cambridge: Cambridge University Press.

Valentin, J. L. (1984). Analyse des parametres hydrobiologiques dans la remotee de Cabo Frio (Bresil). Mar. Biol. 82, 259-276. doi: 10.1007/bf00392407

Ventura, C. R. R., Borges, M., Campos, L. S., Costa-Lotufo, L. V., Freire, C. A., Hadel, V. F., et al. (2013). "Echinoderm research and diversity in Latin America," in Echinoderm Research and Diversity, eds J. J. Alvarado and F. A. Solis-Marin (Berlin: Springer), 301-344.

Vergés, A., Steingerg, P. D., Hay, M. E., Poore, A. G. B., Campbell, A. H., Ballesteros, E., et al. (2014). The tropicalization of temperate marine ecosystems: climate-mediated changes in herbivory and community phase shifts. Proc. R. Soc. B 281:20140846. doi: 10.1098/rspb.2014.0846

Williams, I. D., and Polunin, N. V. C. (2001). Large-scale associations between macroalgal cover and grazer biomass on mid-depth reefs in the Caribbean. Coral Reefs 19, 358-366. doi: 10.1007/s003380000121

Conflict of Interest: The authors declare that the research was conducted in the absence of any commercial or financial relationships that could be construed as a potential conflict of interest.

Copyright (c) 2020 Cordeiro, Harborne and Ferreira. This is an open-access article distributed under the terms of the Creative Commons Attribution License (CC BY). The use, distribution or reproduction in other forums is permitted, provided the original author(s) and the copyright owner(s) are credited and that the original publication in this journal is cited, in accordance with accepted academic practice. No use, distribution or reproduction is permitted which does not comply with these terms. 